\title{
Aspectos morfológicos dos verbos na língua Mehináku (Arawak)
}

\author{
Paulo Henrique Pereira Silva de Felipe \\ Universidade Estadual de Campinas (UNICAMP), Campinas, São Paulo, Brasil \\ pauloh2sp@gmail.com \\ https://orcid.org/0000-0001-6607-5417
}

DOI: http://dx.doi.org/10.21165/el.v47i1.1924

\begin{abstract}
Resumo
O objetivo principal deste trabalho é apresentar uma análise inicial da morfologia dos verbos na língua Mehináku (Arawak). Os verbos, nesta língua, dividem-se transitivamente em dois tipos: (i) verbos transitivos, que requerem dois argumentos obrigatórios (um agente/sujeito como argumento externo e um objeto como argumento interno) e (ii) verbos intransitivos, que admitem apenas um argumento (um agente/sujeito como argumento externo). Do ponto de vista morfológico, os verbos são acompanhados por prefixos pronominais, que geralmente representam o argumento externo da construção, além de sufixos marcadores de tempo e aspecto. Os argumentos internos não são marcados no verbo, mas expressos sintaticamente.
\end{abstract}

Palavras-chave: língua Mehináku; verbos; morfologia verbal.

\section{Morphological aspects of the verbs in Mehináku language (Arawak)}

\begin{abstract}
The main objective of this work is to present an initial analysis of the morphology of the verbs in Mehináku (Arawak) language. Verbs, in this language, are transitively divided into two types: (i) transitive verbs, which require two obligatory arguments (an agent/subject as an external argument and an object as an internal argument) and (ii) intransitive verbs, which admit only an argument (an agent/subject as an external argument). From the morphological point of view, verbs are accompanied by pronominal prefixes, which generally represent the external argument of the construction, as well as time and aspect suffixes. The internal arguments are not marked in the verb, but expressed syntactically.
\end{abstract}

Keywords: Mehináku language; verbs; verbal morphology.

\section{Considerações iniciais}

Embora mais de 500 anos tenham se passado desde a chegada dos colonizadores em terras brasileiras e de seu eminente contato com os povos indígenas que aqui viviam, muito pouco ainda se sabe a respeito das línguas e culturas desses povos. As comunidades indígenas têm enfrentado, ao longo do tempo, significativos entraves, que começaram desde o próprio período de colonização, com a exploração das riquezas materiais indígenas, a catequização e o genocídio sofrido por esses povos, até, atualmente, momento em que os povos indígenas ainda se veem tolhidos de seus direitos fundamentais de acesso à terra e de garantia de seus direitos civis.

Todo esse processo de atravancamento se reflete, por sua vez, na produção científica a respeito dos povos indígenas, que mesmo depois de mais de cinco séculos, ainda é pequena, se comparada aos estudos sobre línguas românicas, germânicas, dentre 
outras. Pensando, portanto, na necessidade de se registrar as produções indígenas, que se configuram como provas inescapáveis da história desses povos, é que propomos, neste trabalho, apresentar uma análise linguística inicial da morfologia dos verbos da língua Mehináku (Arawak). Acreditamos que, embora de forma ainda incipiente, esse trabalho possa contribuir para o conhecimento de alguns aspectos formais da língua em análise.

A fim de cumprir com nosso objetivo, este trabalho está dividido em duas partes, quais sejam: a seção 1, em que falaremos sobre a língua e o povo Mehináku, sua localização, número de falantes e divisão das aldeias e a seção 2, destinada propriamente à apresentação da estrutura morfológica dos verbos em Mehináku, na qual exibiremos os pronomes pessoais que se anexam ao verbo, bem como os morfemas verbais de tempo e aspecto, que conseguimos depreender a partir de nossa análise.

\section{A língua e o povo Mehináku}

Os índios Mehináku do Brasil central são, segundo Gregor (1982), apenas umas das aldeias muito similares que vivem ao longo dos formadores do rio Xingu, um dos grandes tributários do Amazonas. De acordo com o Instituto Socioambiental (ISA, 2006), os Mehináku são habitantes da área cultural conhecida como Alto Xingu e fazem parte de um amplo complexo de povos que, embora compartilhem de muitas semelhanças, especialmente em relação à língua e à cultura, são diferentes entre si.

Os Mehináku falam uma língua de mesmo nome, ${ }^{1}$ pertencente à família Arawak. Ainda de acordo com o ISA (2006), estima-se que a língua Mehináku seja falada por aproximadamente 250 pessoas que habitam a região do rio Kurisevo, no Parque Indígena do Xingu, Mato Grosso, Brasil. Em pesquisa de campo recente, entretanto, percebemos que esse número está desatualizado, uma vez que somente na aldeia Utawana há cerca de 180 indígenas. Acreditamos, portanto, que a língua Mehináku seja falada, atualmente, por mais de 400 indígenas.

A população distribui-se em quatro aldeias, são elas: (i) Uyaipiyuku, que é a mais antiga e da qual derivaram as demais aldeias, e que é dirigida pelo cacique Yumui Mehináku; (ii) Utawana, que desde o início de 2016 tem sido dirigida pelo cacique (e também pajé) Tukuyari; (iii) Kaupüna, que foi criada por Makaulaka Mehináku, filho de Yahati Mehináku (antigo cacique da aldeia Utawana), após ter retornado da Universidade de Brasília, onde fez seu mestrado em Linguística e (iv) Aturua, atualmente dirigida pelo cacique Amunai, irmão do cacique da aldeia Uyaipiyuku. A aldeia Utawana é a mais próxima da cidade, localizada a cerca de 35 quilômetros da cidade de Gaúcha do Norte (MT) e mantém certa proximidade com as aldeias Kaupüna e Aturua, de modo que é possível se locomover de uma à outra mais rapidamente. A aldeia Uyaipiyuku, por sua vez, é a mais distante das quatro mencionadas acima, e está situada a aproximadamente quatro horas de viagem de barco da aldeia de Utawana.

Nossa pesquisa de campo foi feita na aldeia Utawana, segunda maior entre as quatro aldeias habitadas por povos Mehináku. A aldeia tem 11 casas dispostas em formato de círculo, e outras duas casas que ficam próximas à base de enfermagem. As 11 casas que compõem o círculo que forma o coração da aldeia são construídas com madeira e

\footnotetext{
${ }^{1}$ De acordo com os indígenas, Mehináku é o nome dado pelo "homem branco" à língua, em virtude de sua dificuldade em pronunciar adequadamente o nome da língua que, segundo eles, é Imiehünaku (como escrito ortograficamente na língua).
} 
forradas com uma espécie de palha, encontrada nas proximidades. As duas casas que estão fora do círculo são feitas de madeira. Além das casas habitadas pelas famílias Mehináku, há, ainda, uma casa mais afastada e a menor de todas, destinada ao uso escolar.

De acordo com Corbera Mori (2008b), à diferença do que ocorre em alguns outros povos indígenas, no caso do Mehináku há uma correlação entre o número da população e o número de falantes. Todos os membros das quatro aldeias Mehináku falam a língua materna. Os homens de mais de 60 anos são monolíngues, falam apenas a língua indígena. Do mesmo modo, as mulheres mais adultas só falam em Mehináku. As mulheres mais jovens entendem o português, mas o falam muito pouco. Os jovens, ao contrário, falam o português com certa fluidez. Contudo, quando saem para vender artesanato em cidades como Campinas, São Paulo, Brasília, entre outras, gostam de falar em sua própria língua.

\section{A estrutura morfológica dos verbos em Mehináku}

Os verbos podem ser caracterizados de diferentes pontos de vista. Do ponto de vista semântico, por exemplo, os verbos referem-se, segundo Schachter e Shopen (1985), às classes gramaticais, ou partes do discurso, nas quais ocorrem as palavras que expressam ações, processos, estados ou mudança de estado do sujeito. Morfologicamente, por outro lado, o verbo é a classe que inclui categorias de gênero, pessoa, número, modo, tempo, aspecto, voz, dentre outras, enquanto, do ponto de vista sintático, os verbos estabelecem relações com nomes (sujeito/predicado; agente/ação; paciente/ação).

Nos ateremos, neste trabalho, à caracterização morfológica dos verbos em Mehináku (Arawak), sobretudo no que se refere à apresentação dos elementos, entendidos aqui como morfemas, que os compõem. Não deixaremos de tratar, todavia, da relação sintática que os verbos estabelecem com outros elementos, quando necessário.

Os verbos, em Mehináku, dividem-se transitivamente em dois tipos: (i) verbos transitivos, que requerem dois argumentos obrigatórios (um agente/sujeito como argumento externo [Arg. 1] e um objeto como argumento interno [Arg. 2]), conforme (01a/b), abaixo, e (ii) verbos intransitivos, que admitem apenas um argumento (um sujeito como argumento externo [Arg. 1]), como em (01c/d). Vejamos:

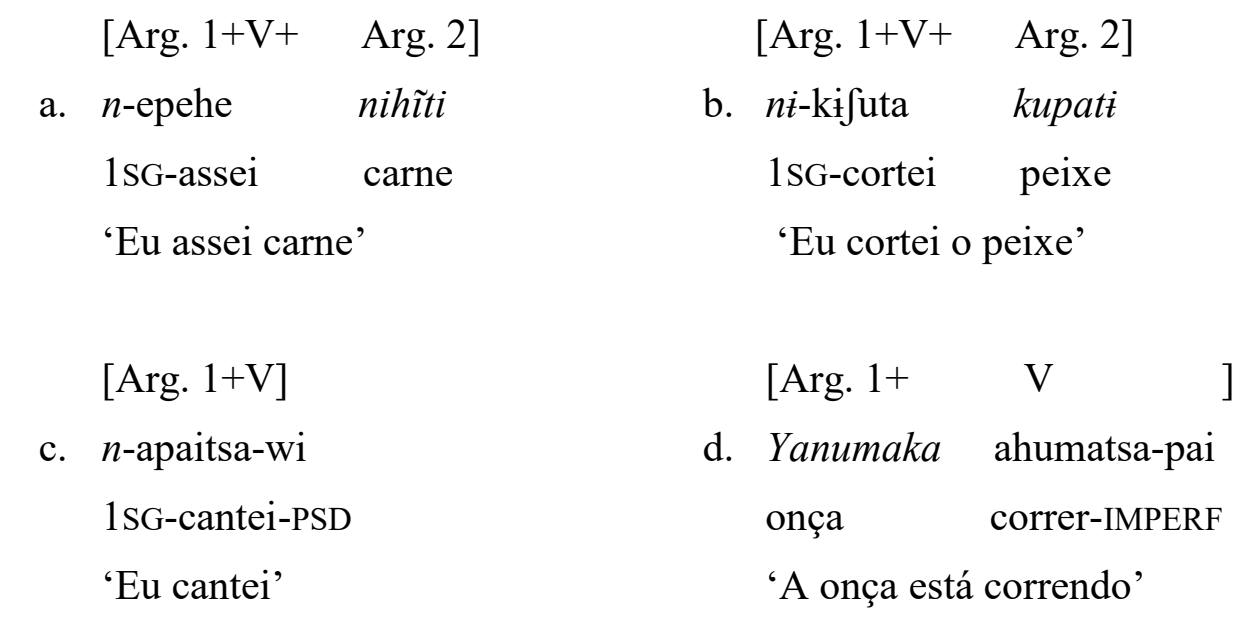


Reparemos, pelos exemplos apresentados acima, que aos verbos são combinados alguns afixos. O sujeito pronominal, por exemplo, é marcado por meio de um prefixo à esquerda do predicado, como em (01a-c), enquanto categorias como as de tempo passado, como em (01c) e aspecto imperfectivo, em (01d), são marcadas por meio de sufixos à direita do verbo. Nas subseções seguintes, conheceremos um pouco mais a respeito desses morfemas, a fim de que possamos compreender melhor a estrutura morfológica dos verbos em Mehináku.

\subsection{Os prefixos pronominais}

Conforme vimos acima, alguns pronomes pessoais aparecem adjungidos prefixalmente à esquerda dos verbos. Estamos assumindo, neste trabalho, que estes prefixos pronominais são formas reduzidas dos pronomes pessoais plenos da língua Mehináku. Nossa decisão leva em consideração, sobretudo, o sistema de marcação de posse da língua, que apresenta os mesmos tipos de pronomes reduzidos, mas anexados aos nomes.

A relação entre pronomes plenos e reduzidos que aqui assumimos pode ser vista no Quadro 1, abaixo, em que apresentamos à esquerda os pronomes plenos da língua, e à direita suas respectivas formas reduzidas, quando em adjunção aos verbos, com seus também respectivos alomorfes. Vejamos:

Quadro 1. Relação entre pronomes plenos e reduzidos em Mehináku

\begin{tabular}{l|l|l|l|l|l}
\hline Glosas & Formas Plenas & & Formas Reduzidas & & Alomorfes \\
\hline $1 \mathrm{SG}$ & natu & $\longrightarrow$ & nu- & $\longrightarrow$ & ni- $\sim$ na- $\sim$ ni- $\sim$ ne- $\sim$ n- \\
\hline 2SG & pitsu & $\longrightarrow$ & pi- & $\longrightarrow$ pa- $\sim$ pi- $\sim$ pe- $\sim$ pu $\sim$ p- \\
\hline 3 SG & $\varnothing$ & $\longrightarrow$ & i- & $\longrightarrow$ & i- $\sim$ in- \\
\hline 1 PL & aitsu & $\longrightarrow$ & aw- & a- \\
\hline 2PL & jitsu & $\longrightarrow$ & ji- & ji- \\
\hline 3PL & $\varnothing$ & $\longrightarrow$ & i- & i- $\sim$ in- \\
\hline
\end{tabular}

Alguns exemplos de uso desses prefixos pronominais em Mehináku podem ser vistos em (02), a seguir:

a. nu-tuka-wi-ku

1SG-beber-PSD-DECL

'Eu bebi'

c. Ø-tuka-wi-ku

3SG/PL-beber-PSD-DECL

'Ele/Eles beberam' b. pu-tuka-wi-ku

2SG-beber-PSD-DECL

'Você bebeu'

d. Aw-tuka-wi-ku

1PL-beber-PSD-DECL

'Nós bebemos'

Como vimos, acima, os prefixos pronominais em Mehináku apresentam muitas formas alomórficas. Essa variedade alomórfica se dá, a nosso ver, em virtude dos processos morfofonológicos dos quais participam esses pronomes. Um desses processos, por exemplo, é a harmonização vocálica. Os pronomes reduzidos em Mehináku sofrem 
um processo de harmonização vocálica a depender do tema (verbal ou nominal) a que se anexam.

Em (03a), por exemplo, é possível ver que a vogal do prefixo pronominal, que em sua forma reduzida é u-, como em nu-, se transforma em i-, como em ni-, por harmonizarse vocalicamente com a primeira vogal do tema verbal que o segue. Em (03b), por sua vez, essa mudança não ocorre, pois, a primeira vogal do tema nominal pulanuma 'barba' coincide com a vogal do prefixo de primeira pessoa nu-, em sua forma reduzida.

$$
\begin{array}{ll}
\text { a. ni-kifuta araukuma } & \text { b. } \\
\text { 1SG-cortei galinha } & \text { 1sG-barba } \\
\text { 'Eu cortei a galinha' } & \text { 'Minha barba' }
\end{array}
$$

Mas há, ainda, em Mehináku, outro fenômeno interessante que ocorre com os pronomes quando estes estão adjungidos aos verbos ou nomes: podem sofrer apagamento vocálico quando o tema que os segue se inicia por vogal. Vejamos esse processo em (04), a seguir, em que [Ø] indica a vogal apagada:

a. $\mathrm{n}[\varnothing]$-apaitsa-wi-ku

1SG-cantei-PSD-DECL

'Eu cantei' b. n-ana

1SG-pilão

'Meu pilão'

\subsection{A categoria de Tempo Verbal}

O tempo verbal, segundo Comrie (1976), está relacionado a uma situação que se refere a outro tempo de fala. Assim, as noções de presente, passado e futuro, ou seja, os três tempos verbais mais comuns à maioria das línguas do mundo descrevem, respectivamente, o momento simultâneo, o momento anterior e o momento subsequente ao tempo de fala, ou, em outras palavras, ao momento de enunciação.

Em seu tradicional esboço da escala temporal, Comrie (1985b) assinala um marco zero, que representaria o tempo presente, estando todas as ações relativas ao passado assinaladas à esquerda, enquanto todas as ações relativas ao futuro estariam dispostas à direita desta escala. Vejamos este esboço no quadro abaixo.

Quadro 1. Representação para a análise do tempo

Fonte: Comrie (1985b, tradução nossa)

Nesta escala, parecem-nos muito bem assinaladas as noções de tempo presente, passado e futuro.

Pela análise inicial da morfologia verbal do Mehináku, contudo, conseguimos perceber que esta língua não parece fazer distinção entre passado, presente e futuro, como proposto na escola de Comrie (1976), mas apenas entre passado e não-passado, uma vez 
que o presente não é marcado morfologicamente na língua. As ações no presente, neste idioma, parecem estar ligadas ao aspecto imperfectivo, ou seja, a um período de tempo em curso, não acabado.

Nesse sentido, concordamos com Comrie (1976, p. 66, tradução nossa), quando o autor afirma que "uma vez que o tempo presente é essencialmente usado para descrever, em vez de narrar, ele é essencialmente imperfectivo, contínuo ou habitual, e não perfectivo", conforme veremos na seção seguinte.

Os tempos passado e não-passado (incluindo-se nesse ínterim o futuro), em contrapartida, são morfologicamente marcados em Mehináku. O passado é marcado pelo morfema [-wi], que vem adjungido à direita do verbo, e é utilizado na língua para indicar ações que antecedem o momento da enunciação, ou seja, que já ocorreram. Vejamos, em (05), abaixo, exemplos de construções predicativas no passado.
a. n-aitfa-wi-ku
b. n-utuka-wi-ku
1SG-comer-PSD-DECL
1SG-beber-PSD-DECL
'Eu comi'
'Eu bebi'

Esses sufixos, assim como ocorre com os prefixos que mostramos na seção anterior, podem sofrer harmonização vocálica, a depender da natureza da última vogal do tema a que estão anexados. É possível encontrar, por exemplo, alguns alomorfes dos morfemas de tempo, como [-wi], para o tempo passado, e [li] , para o tempo futuro, quando a última vogal do tema a que se adjungem for central. Nesses casos, como é possível ver, a vogal do morfema (sufixo) se combina com a vogal do tema.

O tempo futuro, por sua vez, é expresso morfologicamente no verbo por intermédio do sufixo [-la], conforme é possível ver nos exemplos em (06) seguintes. Este sufixo é responsável por indicar que o momento de ocorrência do fato enunciado é posterior à própria enunciação.
a. aw-apaitsa-la
b. pi-t $\int^{2}$ atumala-la
1PL-canter-FUT
2SG-trabalhar-FUT
'Nós cantaremos'
'Você trabalhará'

Estamos assumindo, neste trabalho, que estes morfemas se comportam como marcas de tempo futuro, em especial porque se comportam de forma análoga à dos morfemas marcadores de tempo passado.

\subsection{A categoria de Aspecto Verbal}

De acordo com Lyons (1977), diferentemente do tempo, o aspecto não constitui uma categoria dêitica e também não faz referência ao momento da enunciação. $O$ aspecto está relacionado, nesse sentido, ao movimento, ao modo como se produz uma ação, ao resultado da ação, isto é, à constituição temporal interna dos eventos (TRASK, 2006).

\footnotetext{
${ }^{2}$ Ocorre, em Mehináku, uma palatalização das consoantes oclusivas quando estas são antecedidas por i-.
} 
A noção de aspecto, segundo Comrie (1985b), é a menos discutida entre as línguas do mundo, de modo que as noções de aspecto mais conhecidas na tradição gramatical e nos estudos linguísticos são, em geral, as de perfectividade (de ação acabada, realizada) e imperfectividade (ação inacabada).

Há, entretanto, para além somente das noções de aspecto perfectivo e aspecto imperfectivo, outros tipos de aspecto encontrados nas línguas do mundo, como o aspecto prospectivo, que indica uma ação que ainda está por vir/por acontecer; o aspecto frustrativo, que assinala ações que, por alguma razão, não foram concluídas ou foram quase concluídas; o aspecto inceptivo, que é responsável por assinalar o início de uma ação, e assim por diante.

Em Mehináku, até o presente momento, encontramos dois tipos de aspecto verbal: o perfectivo e o imperfectivo.

Diferentemente do aspecto perfectivo (ação completada), o aspecto imperfectivo chama a atenção para a duração de uma ação. De modo geral, enquanto o tempo verbal designa a constituição temporal externa, a noção de aspecto é responsável pelas diferentes maneiras de se perceber ou de se observar a constituição temporal interna de uma situação (COMRIE, 1976).

Nessa língua, parece haver uma distinção clara entre a marcação de aspecto e a de tempo, uma vez que o aspecto perfectivo (ação acabada) é não-marcado (ou marcado pelo morfema zero $[-\varnothing]$ ), enquanto o aspecto imperfectivo (ação não acabada) é marcado no verbo por meio do morfema -pai.

Estamos afirmando que as noções de tempo e aspecto são claramente distintas nesta língua sobretudo porque as marcas morfológicas encontradas nos verbos são diferentes entre si. Assim, se observarmos o caso da marcação de passado em Mehináku, veremos que o morfema utilizado para assinalar essa noção é muito diferente daquele utilizado para marcar ações acabadas e, portanto, o aspecto perfectivo nessa língua.

Vimos, há pouco, que o aspecto perfectivo é não-marcado, ao contrário do que vimos com o tempo passado, que embora também sinalize ações que ocorreram num passado e que, portanto, já terminaram, é marcado por meio do sufixo [-wi]. A diferença, portanto, entre o aspecto perfectivo e o passado, em Mehináku, é que o aspecto perfectivo parece indicar ações que ocorreram no passado, mas que não podem ser determinadas categoricamente no tempo.

Em outros termos, os verbos são não marcados quando não se determina em que momento do passado a ação enunciada terminou. É possível, por exemplo, que um fato tenha ocorrido e terminado há mil anos, há cem anos, há dez anos ou há poucos minutos. Nestes casos, o verbo não recebe nenhuma marcação morfológica, como podemos ver pelos exemplos em (07), abaixo:

$\begin{array}{llll}\text { a. ni-kifuta- } \varnothing \quad \text { kupati } & \text { b. } & \text { aw-tukapi- } \varnothing & \text { uni } \\ \text { 1SG-cortei-PERF peixe } & \text { 1PL-bebemos-PERF água } \\ \text { 'Eu cortei o peixe' } & \text { 'Nós bebemos água' }\end{array}$


O aspecto imperfectivo, por sua vez, é marcado pelo sufixo -pai e é utilizado, como já dissemos, para indicar ações/fatos não acabados. Este aspecto parece abarcar, em Mehináku, duas noções: uma de habitualidade, ou seja, de uma ação que costuma acontecer sempre e, por isso, é repetitiva, é um hábito; e outra de duração, de continuidade, de uma ação que está em curso no momento da enunciação.

$\mathrm{Na}$ seção anterior, havíamos dito que o Mehináku faz distinção apenas entre passado e não-passado, uma vez que o tempo presente é coberto por marcações aspectuais. Estamos assumindo, assim, que o morfema -pai é utilizado, nesta língua, tanto para marcar acontecimentos que perpassam o presente habitualmente, como em (08a), quanto para marcar acontecimentos que o perpassam de forma contínua, como em (08b). Observemos as sentenças a seguir:

a. n-apaitsa-pai

1SG-cantar-IMPERF.HAB

'Eu canto'

\author{
b. awayulukumã kayayaka-pai \\ cachorro latir-IMPERF.DUR \\ 'O cachorro está latindo'
}

Note-se que, em (08a), temos uma ação não acabada, uma vez que o falante pode ter cantado ontem, pode cantar hoje e pode continuar cantando em momentos seguintes ao da enunciação. O que percebemos é que tal ação se trata de um hábito, motivo pelo qual optamos por tratar a ocorrência do morfema -pai em sentenças desse tipo como "aspecto imperfectivo habitual". Em (08b), por sua vez, temos uma ação contínua, que perpassa o presente. Em ambos os casos, temos ações que perpassam o presente, motivo pelo qual optamos por afirmar que o Mehináku assinala o presente aspectualmente, mas que não podem ter seu início e fim determinados em termos cronológicos. Fica evidente, assim, que estamos tratando da constituição temporal interna dos eventos.

Em termos esquemáticos, poderíamos propor, então, que nossa análise da língua Mehináku revelou dois tipos possíveis de aspecto verbal, conforme mostramos no quadro a seguir:

Quadro 3. Esquema dos tipos de aspecto verbal em Mehináku

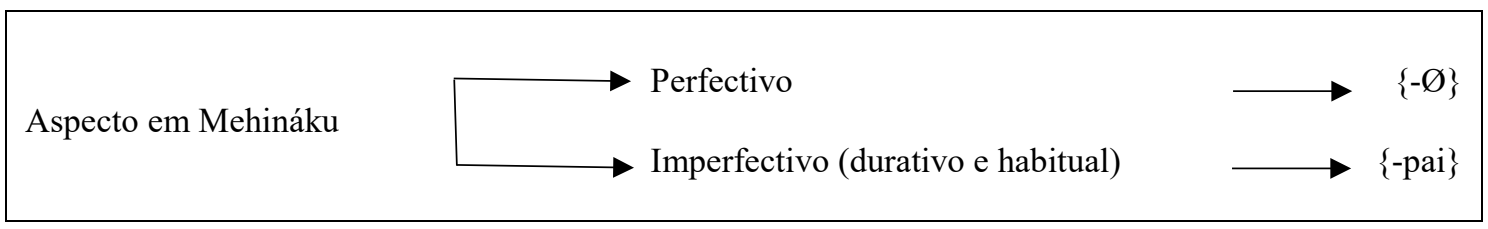

Fonte: Elaboração própria

Um perfectivo representa ações acabadas e é morfologicamente marcado na língua pelo sufixo [-Ø] e um imperfectivo açambarca noções de habitualidade e duração e é representado pelo morfema -pai.

\section{Considerações finais}

Nosso intuito, neste trabalho, foi mostrar, ainda que brevemente, como se comporta a morfologia verbal do Mehináku. Embora este seja um estudo preliminar, já é possível perceber que esta língua apresenta uma morfologia verbal complexa, uma vez que concorrem no verbo, além dos prefixos de pessoa, morfemas de tempo e aspecto. 
Os prefixos de pessoa ocorrem, como vimos, à esquerda do verbo e, quase sempre, em sua forma reduzida. As vogais desses prefixos podem sofrer harmonização vocálica, a depender da qualidade ou natureza da vogal do tema em que tais prefixos estão anexados. Os morfemas de tempo e aspecto, por outro lado, ocorrem à direita do verbo, na forma de sufixos, e suas vogais também podem sofrer harmonização vocálica.

Propomos, neste trabalho, que a língua Mehináku apresenta somente a diferença entre passado e não-passado, bem como dois tipos de aspecto verbal. É possível, entretanto, dado o caráter incipiente desta análise, que outros morfemas possam ser encontrados nessa língua. Acreditamos, por exemplo, que o Mehináku apresente morfemas de modo, sobretudo de modo declarativo, como parece ser a função de -ki, conforme em (03), e, ainda, alguns outros sufixos marcadores de aspecto, que não apenas os que aqui foram apresentados. Há em Mehináku, por exemplo, sentenças como em (09), abaixo:

a. n-ukuti-t fati-keku

1SG-acordar-?-?

'Acabei de acordar'

Nessas sentenças, ainda é preciso determinar a função dos morfemas - $\mathrm{t}$ fati-keku. Nossa hipótese inicial é de que haja, nestes casos, uma marcação aspectual de inceptivo, uma vez que as sentenças parecem assinalar o início de uma ação, mas são necessários novos dados para confirmar tal proposição.

Ademais, ainda conseguimos mostrar, rapidamente, como se comportam os argumentos verbais na língua. Mostramos, por exemplo, que, enquanto o argumento externo do verbo a ele está associado morfologicamente, o argumento interno só é marcado sintaticamente.

\section{REFERÊNCIAS}

AIKHENVALD, A. Y. The Arawak language family. In: DIXON, R. M. W.; AIKHENVALD, A. Y. (Eds.). The Amazonian languages. Cambridge: Cambridge University Press, 1999.

Areal diffusion, genetic inheritance, and problems of subgrouping: a north arawak case study. In: AIKHENVALD, A. Y.; DIXON, R. M. W. (Eds.). Areal diffusion and genetic inheritance. Oxford: Oxford University Press, 2001. p. 167-194.

AWETÍ, M. M. Uma descrição preliminar das classes de palavras da língua Mehináku, com foco especial na classe dos nomes. 2014. 184 f. Dissertação (Mestrado em Linguística) - Universidade de Brasília, Brasília, 2014.

COMRIE, B. Aspect. Cambridge Textbooks in Linguistics. Cambridge: Cambridge University Press, 1976.

1985a.

Language Universals and Linguistic Typology. Oxford: Basil Blackwell,

Tense. Cambridge: Cambridge University Press, $1985 \mathrm{~b}$. 
COMRIE, B.; SMITH, G. Questionnaire. Lingua Descriptive Studies, 1977.

CORBERA MORI, A. Relações entre grafemas e segmentos nos vocabulários Waurá e Mehináku de Steinen (1866[1940]). Revista de Estudos da Linguagem, UESB, Salvador, n. 3, p. 143-157, 2006.

Correspondencias entre grafemas y segmentos en los vocabularios Waurá e Mehináku de Steinen (1866[1940]). Baciyelmo (Letras. Imágenes. Creación), v. 2, p. 7896, 2008a.

Aspectos da fonologia Segmental do Mehináku. Estudos linguísticos, São Paulo, v. 37, n. 1, p. 63-72, 2008 b.

FRANCHETTO, B. Línguas e história no Alto Xingu. In: FRANCHETTO, B.; HECKENBERGER, M. (Orgs.). Os povos do Alto Xingu. História e Cultura. Rio de Janeiro: UFRJ, 2001. p. 111-156.

GREGOR, T. Mehináku: O Drama da vida diária em uma aldeia do alto Xingu. São Paulo: Editora Nacional (Brasiliana), 1982.

INSTITUTO SOCIOAMBIENTAL (ISA). Povos indígenas no Brasil: 2001-2005. São Paulo: Instituto Socioambiental, 2006.

INTERNATIONAL PHONETIC ASSOCIATION (IPA). Handbook of the International Phonetic Association. Cambridge: Cambridge University Press, 1999.

LYONS, J. Semantics. Cambridge: University Press, 1977.

MEHINAKO, M. Imiyehünaku Iyayakatakú (Livro na língua materna do povo Mehinaku). Cáceres: Editora da UNEMAT, 2013.

MENEZES, M. L. P. Parque Indígena do Xingu. Campinas: Editora da UNICAMP, 1999.

RODRIGUES, A. D. Línguas brasileiras. Para o conhecimento das línguas indígenas. São Paulo: Loyola, 1986.

SCHACHTER, P.; SHOPEN, T. Parts-of-Speech systems. In: Language Typology and Syntactic Description: Clause Structure. Second Edition, v.1. Cambridge: Cambridge University Press, 1985.

SILVA, T. C. de S. Estudo preliminar da fonologia da língua Mehináku. 1990. 49 f. Dissertação (Mestrado em Linguística) - Departamento de Linguística, Línguas Clássicas e Vernácula, Universidade de Brasília, Brasília, 1990.

STEINEN, K. von den. Entre os aborígenes do Brasil central. Tradução de Egon Schaden. São Paulo: Departamento de Cultura, 1940[1894].

TRASK, R. L. Dicionário de Linguagem e Linguística. São Paulo: Contexto, 2006.

WISE, M. R. Grammatical characteristics of preandine arawakan languages of Peru. In: DERBYSHIRE, D. C.; PULLUM, G. K. (Eds.). Handbook of Amazonian Languages. v. 1. Berlin: Mouton de Gruyter, 1986. p. 567-642.

Recebido em: 24/08/2017

Aprovado em: 15/02/2018 